\section{Resilience training: how to thrive}

\section{Carolyne Crowe}

Some survive, some cope and others thrive in veterinary practice. The difference is not necessarily the environment they are in or the people in their team, the difference comes from how they view and experience their world, their mind-set, and their beliefs and ultimately how they choose to lead their life. Veterinary practice is always going to be pressurized but it does not need to be stressful. A strategic approach to building resilience across all components that make a team - individuals, systems, teams and practices - is required for sustainable change. However, for the benefit of this lecture we are focusing on what individuals can do to develop their own resilience.

This session identifies key models of how to turn surviving into thriving, giving you practical tools and techniques that will make a difference to you in your daily life in practice.

\section{KEY LEARNING OBJECTIVES}

- Understand the difference between pressure and stress
Learn how to thrive under pressure and understand what works for you

- Identify what is in your control, your influence and what you can do to thrive at work

\section{MULTIPLE CHOICE QUESTIONS}

1. What does thriving mean?

(A) Constantly doing and achieving

(B) Feeling energized at the end of the day

(C) Worrying about what you haven't done in the day

(D) Being 'on' all the time and thinking about work even when at home

2. When you are in your 'green zone' you are which of the following?

(A) Exhausted at the end of the day

(B) Feeling fulfilled and energized by work

(C) Focusing purely on work and not resting

(D) Always putting others first

3. What is a sign of being overwhelmed and in the 'red zone'?
(A) Being unable to switch off
(B) Being present and in the moment
(C) Being highly effective with your communication and working well as a team
(D) Looking after yourself

\section{Mentoring in practice}

\section{Carolyne Crowe}

Positive mentors play an important role in the development of individuals and teams. Developing your own mentoring skills and helping others to grow in confidence and skills can be incredibly rewarding. To enhance others' performance and make your life easier it is vital you understand your own communication and leadership style and how to motivate and engage others effectively. Coaching and mentoring are powerful skills to empower, engage and train your team, but they need to be understood and developed. During this session we will look at practical tools to develop your mentoring skills at work.

\section{KEY LEARNING OBJECTIVES}

- Understand the principles and benefits of mentoring

- Identify actions you can take to be an effective mentor

- Learn practical tools to develop your mentoring skills

\section{MULTIPLE CHOICE QUESTIONS}

1. What is mentoring?
(A) Telling someone what to do
(B) Imparting your experience and knowledge to help others develop
(C) Being focused only on the pastoral aspects of the role
(D) Something that only benefits the mentee

2. What do mentors need?
(A) To be the best in their field
(B) To have a level of experience in the area their mentee works or the situation they are in
(C) To be available 24/7 for their mentee
(D) To become best friends with their mentee

3. What are the benefits of a good mentor?

(A) They reduce confidence and self-esteem

(B) They provide appropriate feedback on the mentee's behaviour and performance

(C) Provide false promises

(D) Try and be everything to the mentee 